\title{
The Extraction of Gold from E-waste by Hydrometallurgy
}

\author{
AZIZ MIKAELI HAMZEH GHASEM and SHAHRZAD KHORAMNEJADIAN* \\ Department of the Environment, Damavand Branch, Islamic Azad University, Damavand, Iran. \\ ${ }^{*}$ Corresponding author E-mail: khoramnezhadian@yahoo.com \\ http://dx.doi.org/10.13005/ojc/310112
}

(Received: December 06, 2014; Accepted: January 10, 2015)

\begin{abstract}
E-waste production in great amounts and its problems, which challenge the field of Waste and Environment Management, stem from the increase in the production of electronic appliances, diversity-seeking consumers, and perishable products. To solve the problems and extract valuable metals by hydrometallurgy, leaching and organic solvent are used. To do this, after a specific amount of electrical and electronic waste was crushed, ground, and refined, it was sampled. Then, the sample was washed with water, and its remaining was leached into nitric acid. As a result, copper and silver were dissolved in it, and considering chemical features, gold remained in solid objects. To dissolve gold, the leached sludge is leached into the mixture of 1 mole nitric acid and 3 moles choric acid. More than 99.92 percent of the dissolved gold with some impurities entered the aqueous phase. The effect of three factors- the proportion of acid, time, and temperature- on the extraction of gold were observed and analyzed: they have no specific impact on the proportion of gold dissolution. Desirable conditions for the test, 60 minutes time, a 1:1 proportion of $\mathrm{Hcl} / \mathrm{HNO}_{3}$, and a temperature of 60 degrees Celsius were used to purify the leached solution with gold and to transfer it to aqueous phase. The achievement of gold, with a result of $98.47 \%$, from waste happened during a single extraction in an aqueous to organic phases with a ratio of 1:10. In other words, less than $2 \%$ of the gold remained in the gold leach solution. Then, the organic phase, which is charged with $2 \mathrm{M}$ ammonium hydroxide solution and $0.5 \mathrm{M}$ sodium thiosulfate, was transferred. The results were not positive, and 3.13 and $15.26 \%$ of gold was transferred from organic to aqueous phase. It is worth mentioning that in case of copper anode sludge in similar situations, 3 and $15 \%$ were achieved, respectively.
\end{abstract}

Key words: Extraction, gold, $0.5 \mathrm{M}$ sodium thiosulfate, leaching, e-waste.

\section{INTRODUCTION}

The fast development of technology has lead to an increase in a new generation of electronic and electrical waste in the world and has seriously threatened the environment and natural resources. E-waste like WPCBs, as the major part of waste, is a considerable source of valuable base metals such as gold, silver, and copper. In recent years, a large number of base and valuable metal recycling activities from PCBs waste have focused on pyrometallurgy process, Kamberovic, et al. ${ }^{10}$ Electronic and electrical waste is usually processed using modern methods like pyrometallurgy and hydrometallurgy. Nonetheless, new solutions for having access to economic benefits and efficient 
environment are being searched for (WILLNER, et al, 2013).E-waste as key component could be used as secondary raw material. It is taken into consideration due to its complex components like PCBs, plastic, glass, ceramics, and valuable metals. It has also drawn a great deal of attention in two recent decades owing to economic and bioenvironmental effects and the excessive decrease in natural resources, Kamberovic, et al. ${ }^{11}$ Recycling and recovery of metals from electrical and electronic waste are needed for the protection of environmental resources and their reuse. The waste's recycling is generally done by pyrometallurgy process; however, since this method is not easily controlled, it brings about fatal gases, and causes the recovery of valuable low metals, hydrometallurgy method is suggested, Kamberovic, et al. ${ }^{11}$ Ever since a century ago, cyanide process has been used to extract gold and other valuable metallic inerals; nevertheless, as cyanide causes poisoning, its use has been prohibited in a numerous countries, Kamberovic, et al .11 In hydrometallurgy method, one selects the solvent, the way of dissolution, and other factors by recognizing the components in the sludge. Creating suitable conditions by recognizing the present components of the sludge may lead to an increase in the output of the operation and metal extraction with a higher karat, Abdollahi, et al. ${ }^{14}$ Leaching as a function of particle size and stirring rate per minute will be tested, and also the effect of phase ratio, mixing time and stirring will be analyzed ,Kamberovic, et al .11

Wong, et al used hydrometallurgy to extract valuable metals like gold, silver, selenium, tellurium from copper anode sludge. In this method, anode sludge without copper is used to extract silver, selenium, and gold. First, anode sludge without copper is leached into a roughly 4-9 molar nitric acid at 40-115 degrees Celsius. Silver, selenium, and tellurium are dissolved in this situation; the waste leached into nitric acid is processed at a high temperature between 40 to 110 degrees centigrade with aqua regia to dissolve gold. At this level, gold, arsenic, antimony, lead, tin, smooth, platinum group metals and small amounts of silver are leached. The leached solution is separated from the waste and then gold, using extraction technique with solvent recovery and then organic phase containing gold and 2 molar or more choleric acid as detergent solution, is extracted from other impurities. Oxalic acid is used to remove residue and extract gold from organic extractor charged with gold. Ultimately, the revived gold is washed with ethanol and then distilled water to extract pure sponge, $99.9 \%$ pure, Wang, et al. ${ }^{12}$ In the hydrometallurgical process of copper anode sludge, valuable metals like gold and silver are extracted as catalysts and antioxidants using sulfuric acid and the presence of ferric ion $\left(\mathrm{Fe}_{2}\left(\mathrm{SO}_{4}\right)_{3}\right)$. In this research, gold leaching will be based on laboratory criterion and copper extraction will be according to laboratory standards and a pilot study ,Kamberovic , et al. ${ }^{11}$ So as to leach electronic and electrical waste and extract gold and silver, ammonium thiosulfate could be used as a leaching agent and copper sulfate could be applied as a catalyst. The effects of copper sulfate and ammonium thiosulfate $\left[\left(\mathrm{NH}_{4}\right)_{2} \mathrm{~S}_{2} \mathrm{O}_{3}\right]$, the environment $\mathrm{PH}$, and pulp mass were analyzed. $56.7 \%$ of gold was extracted in suitable and optimal conditions, which are in 0.1 molar thiosulfate, $40 \mathrm{ml}$ copper sulfate, and 8 hours time. Gold extraction efficiency of $\mathrm{PCBs}$ in the range of $\mathrm{PH}=10-10.5$ may be attributed to the presence of thiosulfate stability and maximum efficiency was calculated as $78.8 \%$ of gold. By increasing $48 \mathrm{~mm}$ copper sulfate, a 30 $\%$ increase in gold extraction can be expected, and its catalytic role in ammonium thiosulfate can be recognized ,Abdollahi , et al. ${ }^{14}$

To dissolve the gold in the copper anode sludge screened process, it was leached into aqua regia, and more than $99 \%$ of the gold solution entered aqueous phase together with impurities. The optimal condition- the duration of 60 minutes, the $1: 1$ ratio of choleric acid to nitric acid, and 60 degrees centigrade of the environment's temperature- was selected so as to purify the leached solution containing gold and transfer it from organic phase to aqueous phase containing solvent extractor. $98 \%$ of gold was extracted in one stage with the ratio of aqueous phase to organic phase being 1:10. The charged organic phase of $2 \mathrm{M}$ ammonium hydroxide solution and $0.5 \mathrm{M}$ sodium thiosulfate solution was transferred to aqueous phase, and 3 and $15 \%$ of gold was transferred to organic phase, Wang, et al. ${ }^{12}$ In order to revive valuable metals like gold, silver, Selenium, and tellurium from copper anode sludge, firstly, anode 
sludge whose copper was removed was highly heated with nitric acid. As a result of this activity, the mentioned elements -silver, selenium, and tellurium- entered the solution. The extraction of silver from the solution was done through $\mathrm{Ag}-\mathrm{Cl}$, and after the extraction of silver chloride, the nitric acid of the achieved solution was removed and was added to the remainder of the hydrochloric acid solution. To extract selenium and tellurium, $\mathrm{SO}_{2}$ was passed through them. The remaining sludge from the action of soaking in nitric acid was treated by aqua regia so that gold and other impurities could be extracted. This was done in high temperatures for 1-4 hours. The solutions containing gold was separated from other impurities by a liquid-liquid extraction technique, and gold with the purity of more than $99.9 \%$ was achieved by a reducing agent, Wang, et al. 12

\section{MATERIALS AND METHODS}

The method used in this research is based on the extraction method of gold and silver from copper anode sludge, sample preparation, and tests conducted in similar situations. First, a mixture of three kilograms of various types of electronic and electrical wastes (PCBs) was chosen, crushed, and ground. Then, a sample was selected according to the need by quartering method; and afterwards, to specify quantitative determination of metals, atomic absorption spectroscopy (AAS) was used. Moreover, so as to specify the gradation of the sample, mesh screens of $140,200,270,325,400$ $\mathrm{mm}$ were used. The needed equipment for leaching, extraction, and transfer include: Separatory funnel , stirrer, heater, thermometer, pipette fillers, pipette in volumes of 5 and $10 \mathrm{ml}$, shaker flask, sulfuric acid, beaker, boiling water bath, mechanical stirrer
SDS-11D model manufactured by Finetech from South Korea, flame atomic absorption spectrometer SPECTR-AA, 220 model made by VARIAN Company from the US, the cyclone stop machine made by Mozely Company, organic solvent extractor of Organic DI-N-octyl sulfide sulfide ,3 M hydrochloric acid,1 $\mathrm{M}$ nitric acid, $2 \mathrm{M}$ transferring ammonium hydroxide material, and $0.5 \mathrm{M}$ sodium thiosulfate. The used equations include: stripping method, McCabe-Thiele diagram, the slope of operating line (phases ratio), and the mass balance equation obtained from atomic absorption results.

\section{Discussion and Results}

At the sample preparation stage, an overall sample of $3 \mathrm{~kg}$ was prepared, and in different levels it was selected according to the need by quartering method. To specify quantitative determination of metals, atomic absorption spectroscopy (AAS) was used. In this method, some of the sample is chosen according to number of karats in the metal and is dissolved in concentrated nitric acid at a high temperature (90-100degrees Celsius) for an hour. After dissolution, the filtered sample and the existent elements in the achieved solution are measured via flame atomic absorption spectrometer. It was observed that the amount of valuable metals considering the quantity compared to copper anode sludge is more than twofold.

Table 1: Comparison of Leach chemical analysis by atomic absorption spectrometry

\begin{tabular}{lcc}
\hline Parameter & Au & Ag \\
\hline Copper anode slime by percent & 3.04 & 6.27 \\
Electronic waste by percent & 6.39 & 11.35 \\
\hline
\end{tabular}

Table 2: Comparative results with leaching of waste water samples

\begin{tabular}{lccc}
\hline Parameter & $\begin{array}{c}\text { Water samples were } \\
\text { weighed before Leach } \\
\text { (gr) }\end{array}$ & $\begin{array}{c}\text { water sample weight } \\
\text { after Leach } \\
\text { (gr) }\end{array}$ & $\begin{array}{c}\text { weight } \\
\text { loss } \\
\text { (gr) }\end{array}$ \\
\hline Copper anode sludge & 100 & 97.8 & $2.2 \mathrm{gr}$ \\
Electronic waste & 100 & 93.7 & $6.3 \mathrm{gr}$ \\
\hline
\end{tabular}


In order to extract gold from electronic waste, first, unwanted elements must be removed from the combination. Thus, copper, silver, and selenium were omitted from waste sludge using hydrometeorology method (acidic leaching). In this research, as the aim is analyzing the extraction of gold, to achieve the waste containing gold, all the three mentioned elements were leached and removed. To reduce acid uses and the hazards of using it (the environment pollution, corrosion and so on), it was decided to do the operations in lower concentrations than Wang limit (2-4 M); at 80, 90, and 100 degrees Celsius; and in 20,40, and 60 minutes time. If copper, silver, and selenium are not completely dissolved, then leach time will be increased.To leach gold, Wang method was used.

The leaching waste from the first step (copper and silver) was operated with nitric acid to dissolve gold at a high temperature between 40 and 110 degrees Celsius with various ratios of choleric acid to nitric acid being 1-10 in minimum time of 60 minutes. At this stage, gold, arsenic, antimony, lead, tin, silica, platinum group metals, and a small amount of silver were leached.

In this research, the waste obtained from the leaching of copper and silver, which contains 0.973 percent of gold, and a mixture of choleric acid, nitric acid were leached with ratios of $1: 1,3: 1,5: 1$, and $7: 1$ at 60, 80, and 100 degrees Celsius in 1, 1.5 , and 2 hours time in $20 \mathrm{~g}$ per liter concentration at the mixing speed of 800 rounds per minute. The results suggested that roughly 99 percent of the gold was able to be extracted.

The Effect of the Ratio of Hydrochloric Acid to Nitric Acid: the initial experiments revealed that like other researchers' results [11,12, and13] in the field of extraction of valuable metals from anode sludge, an increase in the ratio of the two acids does not have much influence on gold dissolution, and the most effect was achieved in a ratio of $1: 1$ in 60 minutes.

Table 3: Comparison of results in the retrieval of colored metals acid leaching process

\begin{tabular}{lcc}
\hline $\mathrm{HCl} \mathrm{HNO}_{3}$ & $\begin{array}{c}\text { Recovery of gold from copper } \\
\text { anode sludge by percent }\end{array}$ & $\begin{array}{c}\text { Recovery of gold from } \\
\text { electronic waste by percent }\end{array}$ \\
\hline $1: 1$ & 99.82 & 99.83 \\
$1: 3$ & 99.85 & 99.87 \\
$1: 5$ & 99.83 & 99.84 \\
$1: 7$ & 99.85 & 99.86 \\
\hline
\end{tabular}

Table 4: Effect of temperature on the recovery

of valuable metals in aqua regia- leaching process

\begin{tabular}{lcc}
\hline $\mathrm{HCl} / \mathrm{HNO}_{3}$ & $\begin{array}{c}\text { Recovery of gold from copper anode } \\
\text { sludge temperatures by percent }\end{array}$ & $\begin{array}{c}\text { Recovery of gold from } \\
\text { electronic waste by percent }\end{array}$ \\
\hline $60 \mathrm{C}$ & 99.86 & 99.92 \\
$80 \mathrm{C}$ & 99.82 & 99.94 \\
$100 \mathrm{C}$ & 99.83 & 99.95 \\
\hline
\end{tabular}

Table 5: Effect of time of recovery of valuable metals in aqua regia - Leaching Process

\begin{tabular}{lcc}
\hline $\mathrm{HCl}_{\mathrm{HNO}}$ & $\begin{array}{c}\text { Recovery of gold from copper } \\
\text { anode sludge by percent }\end{array}$ & $\begin{array}{c}\text { Recovery of gold from } \\
\text { electronic waste by percent }\end{array}$ \\
\hline $60^{\prime}$ & 99.83 & 99.85 \\
$90^{\prime}$ & 99.85 & 99.87 \\
\hline
\end{tabular}


The Effect of Temperature: the conducted analyses and the comparison of them with other researchers' results [11, 12, and13] in the field of extraction of colorful metals in temperatures of 60 , 80, and 100 degrees Celsius showed that as the temperature increases, so does gold dissolution; however, it is not as dramatic as the status of gold extraction from anode sludge. In addition, the maximum influence of temperature was achieved in a concentration of $1: 1$ in 60 minutes time at 60 degrees Celsius.

The Effect of Time: the results of the carried out experiments, the conducted analyses, and the comparison of them with other researchers' results $[11,12$, and13] in the field of extraction of colorful and valuable metals from anode sludge revealed that as the time increases, so does gold dissolution. It is to notify that the majority of gold is dissolved in the first 60 minutes and the optimal conditions are present in a ratio of $1: 1$ of the acids.

As gold is almost completely dissolved in all situations of the experiment, the optimal conditions are selected to be the 1:1 ratio of choleric acid to nitric acid and an hour time like the status in gold extraction from anode sludge.

In order to extract silver from leached solution and other impurities and also extract gold from leached solution from previous stage, waste extraction with solvent method was used.

One of the methods of purification or metal concentration from leached solution is solvent extraction method.

Organic solvent extraction method is a chemical process in which the present metal in the aqueous phase reacts with an organic substance to create a metal complex. Consequently, the components of the metal leave aqueous phase and enter organic phase. The present metal in organic phase has no bond with carbon atoms as organometallic compounds but has covalent bonds with oxygen, nitrogen, sulfur, or hydrogen.

In this research, waste with a high karat was dissolved in nitric acid and gold was extracted by thioethers, and then it was transferred into aqueous phase by water so that the concentrated solution could be achieved from pure uranyl nitrate.

After transferring the metal from aqueous phase to organic phase, there is a need to transfer it back to aqueous phase by a suitable chemical substance. At this stage, the two aqueous and organic phase mix together and after reaching equilibrium, they get separated. With measuring the amount of metals in aqueous phase, its distribution in aqueous and organic phase could be determined. The ratio of the two phases plays a crucial role in the solvent extraction process. Even though the low ratio of organic phase to aqueous phase theoretically is a privilege, it is sometimes not favorable. On the other hand, the high ratio of organic phase to aqueous one requires a large amount of solvent, which in turn may bring about extra expenses.

Since complete extraction of a dissolved substance at a stage requires extremely huge amounts of solvent, multi-staged extraction is used. Basically, using a limited amount of solvent substance gives rise to a complete extraction.

To purify or concentrate the leaches solution, extractors are used.

The achieved leached solution from the dissolution of waste containing gold was used at 60 degrees Celsius in a 1:1 ratio of choleric acid to nitric acid for 60 minutes in order to purify the gold. Gold is extracted from other impurities by organic solvent extraction techniques using DI-N-octyl sulfide as an organic extractor and $2 \mathrm{M}$ or more choleric acid as detergent solution for aqueous phase. In this research, the used leached solution was obtained from waste dissolution from silver and other unwanted metals omission stage. At the first step of leaching, it was leached into choleric acid and nitric acid with a ratio of $1: 1$ at 60 degrees Celsius in an hour time, and the concentration of gold in the solution equaled $94 \mathrm{mg} / \mathrm{l}$.

The stirring time for mixing the two phases was selected to be approximately 60 minutes. The separation time for the two phases was 15 minutes. The organic phase amount is stable in all situations $(5 \mathrm{ml})$, and the aqueous phase amount changes 
according to the ratio of the two phases. The results suggest that as the two phases decrease, the size of gold extraction increases slightly and the maximum extraction efficiency is related to $3: 1$ ratio of the two phases. In aqueous phase, gold was analyzed by atomic absorption spectrometry (AAS), and its amount was determined by mass balance in organic phase.

Table 6: Results of the extraction of gold by sx the extraction of gold in the presence of organic matter D - $n$ - Aktyle sulfide

\begin{tabular}{lccc}
$\mathrm{HCl} \mathrm{HNO}_{3}$ & $\theta=90^{\circ} \mathrm{C}$ & $\mathrm{T}($ mixed $)=120$ & $\mathrm{~V}($ sample $)=$ constant \\
\hline $\mathrm{HCl}^{\mathrm{HNO}}{ }_{3}$ & $\begin{array}{c}\text { Extraction of gold from copper } \\
\text { anode sludge by percent }\end{array}$ & $\begin{array}{c}\text { Extracting gold from } \\
\text { electronic waste by percent }\end{array}$ \\
\hline $1: 1$ & 99.94 & 99.99 \\
$1: 10$ & 99.33 & 98.47 \\
\hline
\end{tabular}

Table 7: Stripping gold from the organic phase to aqueous phase with the ammonium hydroxide

\begin{tabular}{|c|c|c|c|}
\hline $\mathrm{HCl} / \mathrm{HNO}_{3}$ & $\theta=90^{\circ} \mathrm{C}$ & $T($ mixed $)=120$ ، & $\mathrm{V}($ sample $)=$ constant \\
\hline $\mathrm{HCl} / \mathrm{HNO}_{3}$ & $\begin{array}{l}\text { Stripping } \\
\text { anode } s\end{array}$ & $\begin{array}{l}\text { f gold from copper } \\
\text { udge by percent }\end{array}$ & $\begin{array}{l}\text { Stripping gold from electronic } \\
\text { waste by percent }\end{array}$ \\
\hline 1:1 & & 0.98 & 3.1 \\
\hline $1: 10$ & & 0.99 & 3.13 \\
\hline
\end{tabular}

Table 8: Stripping gold from the organic phase to the aqueous phase with sodium thiosulfate $\left(\mathrm{Na}_{2} \mathrm{~S}_{2} \mathrm{O}_{5}\right)$

\begin{tabular}{|c|c|c|}
\hline $\mathrm{HCl} / \mathrm{HNO}_{3}$ & $T($ mixed $)=12$ & $\mathrm{~V}($ sample $)=$ constant \\
\hline $\mathrm{HCl} / \mathrm{HNO}_{3}$ & $\begin{array}{l}\text { Extraction of gold from copper } \\
\text { anode sludge by percent }\end{array}$ & $\begin{array}{l}\text { Extracting gold from } \\
\text { electronic waste by percent }\end{array}$ \\
\hline $1: 1$ & 6.01 & 15 \\
\hline $1: 10$ & 6.18 & 15.26 \\
\hline
\end{tabular}

After gold was extracted from the leach solution by selectively organic extractor and entered organic phase, the possibility of gold transfer using 2M ammonium hydroxide solution was analyzed as follows:

Stirring the mixture of the two phases needs 30 minutes, the separation takes 20 minutes, and the volume of organic and aqueous phase considered to be each $5 \mathrm{ml}$.
The charged organic phase by the gold, which was related to the experiment of gold extraction from charged organic phase, was used for stripping. The organic and aqueous phases were mixed with a ratio of $1: 1$ and after reaching equilibrium, they separated. Then, the transferred gold to aqueous phase by atomic absorption spectroscopy (AAS) and its amount was determined by mass balance in organic phase. 
The results suggest that at the most $3 \%$ gold was stripped by $2 \mathrm{M}$ Hydroxide ammonium, which was not satisfactory. Moreover, sodium thiosulfate was used to strip gold from organic phase using Martins et al method, which obtained successful results in Abdollahi et al project. As a result, in this research, the possibility of gold transfer from organic phase (DNOS) by $0.5 \mathrm{M}$ sodium thiosulfate was analyzed. To do so, the organic phase of DNOS charged by gold and the aqueous phase of $0.5 \mathrm{M}$ sodium thiosulfate were mixed with a ratio of $(A / O)$ 1:1, 2:1, 4:1, 6:1 and after reaching equilibrium in 15 minutes, they separated. Afterwards, the transferred gold to aqueous phase was measured by AAS, and its amount in organic phase was determined by mass balance. The results reveal that gold extraction in the mentioned method, and in the acidic ratio of 1:1 in 2hours time at 90 degrees Celsius, is 2.5 times more than anode sludge or $15.26 \%$.

\section{CONCLUSION}

The fast pace of development in technology has lead to an increase in a new generation of electrical and electronic waste, which is a great threat against the environment and natural resources in the world. To resolve this problem and achieve valuable metals from electrical waste, hydrometallurgy was used through leaching process and organic solvent extraction.

To do this, after a specific amount of electric and electronic waste was crushed, ground, and refined, it was sampled. Then, the sample was washed with water, and its remaining was leached into nitric acid. As a result, copper and silver were dissolved in it, and considering chemical features, gold remained in solid objects. To dissolve gold, the leached sludge was leached into the mixture of $1 \mathrm{M}$ nitric acid and $3 \mathrm{M}$ choric acid. More than 99.92 percent of the dissolved gold with some impurities entered the aqueous phase. The effect of three factors, the proportion of acid, time, and temperature, on the extraction of gold was observed and analyzed: they have no specific impact on the proportion of gold dissolution. Desirable conditions for the test, 60 minutes time, a $1 / 1$ proportion of $\mathrm{HCl} / \mathrm{NO}_{3}$, and a temperature of 60 degrees Celsius were used to purify the leached solution with gold and to transfer it to aqueous phase. The achievement of gold, with a result of $98.47 \%$, from waste happened during a single extraction in an aqueous to organic phases with a ratio of $1: 10$. In other words, less than $2 \%$ of the gold remained in the gold leach solution. Then, the organic phase, which was charged with $2 \mathrm{M}$ ammonium hydroxide solution and $0.5 \mathrm{M}$ sodium thiosulfate, was transferred.

To do so, the organic phase of DNOS charged by gold and the aqueous phase of $0.5 \mathrm{M}$ sodium thiosulfate were mixed with a ratio of $(\mathrm{A} / \mathrm{O})$ $1: 1,2: 1,4: 1,6: 1$ and after reaching equilibrium in 15 minutes, they separated. Afterwards, the transferred gold to aqueous phase was measured by AAS, and its amount in organic phase was determined by mass balance. The results reveal that gold extraction in the mentioned method, and in the acidic ratio of $1: 1$ in 2 hours.

\section{ACKNOWLEDGMENTS}

These article research based on $\mathrm{MsC}$ thesis of Aziz Mikaeli Hamzeh Ghasem under supervision of Dr.shahrzad khoramnejadian.

\section{REFERENCES}

1. Tripathi,A .; Kumar,M.; Sau ,D. C.; Agrawal ,A.; Chakravarty ,S.; Mankhand ,T. R. International Journal of Metallurgical Engineering, 2012, 1(2), 17-21 .

2. Brigden,K.; Labunska, I.; Santillo, D.; Johnston, P. Greenpeace International ,2008.

3. Cui, J.; Zhang, L. Journal of Hazardous
Materials, 2008 , 158,228-256.

4. Darby, L.; Obara, L.; Household recycling behaviour and attitudes towards the disposal of small electrical and electronic equipment. Resources, Conservation and Recycling, 2005 , 44, 17-35.

5. Du Plessis, J. Environment and 
Urbanization, 2005 , 17(1).

6. Fasko, R.; Müller, E.; Schluep, M.Estimation of Dioxin Emissions from Cable Burning in the Greater Accra Region, 2010.

7. Jorgensen,F. E. 22nd Annual college and university Hazardous Waste conference, 2004,7.

8. Li, J.H.; Honda ,S.; Liu, T.Z. Proceedings of the Third Workshop on Material Cycles and Waste Management in Asia, Tsukuba, Japan, 2004.

9. Joanna,W.; Agniszka, F. Extraction OF Metals From Electronic Waste by Bacterial Leaching Environment Protection Engineering , 2013 , 39 , 1 ,DOI: 10.5277/ EPE130115 .

10. Zeljko , K.; Marija,K.; Dragana ,I.; Vesna ,N.;Milisav ,R . Association of Metallurgical
Engineers of Serbia[AMES], 2011,Scientific paper,UDC: 661.061.34:628.4.043.

11. Kamberovic, Z.; Korac, M.; Ranitovic ,M. Faculty of Technology and Metallurgy, University of Belgrade, Serbia Association of Metallurgical Engineers of Serbia [ AMES ],2011,Scientific paper UDC: 628.477.6

12. Wang,T.G . Hyrometallurgical process for recovering precious metals from nodeslimes, 1981, US.Patent 4293332.

13. Saeedi, M.; Alamdari, E. K.; Fatmehsari,D. H. Department of Mining and Metallurgical Engineering, Amirkabir University of Technology. $2013.23^{\text {rd }}$ International Mining Congress \& Exhibition of Turkey, ANTALYA .

14. Abdullahi,M.; kolaini,M. ; vafaei fard, S. M. J. Iranian Journal of Chemistry and Chemical Engineering 2007. 